\title{
Strong book on building community through food
}

\author{
Review by Amy Crone* \\ Maryland Farmers Market Association
}

Review of G ood F ood, Strong C ommunities: Promoting Social Justice through L ocal and Regional F ood Systems, edited by Steve Ventura and Martin Bailkey. (2017). Published by University of Iowa Press. Available as paperback and ebook; 304 pages. Publisher's website: https:// www.uipress.uiowa.edu/ books/ 9781609385439/good-food-strong-communities

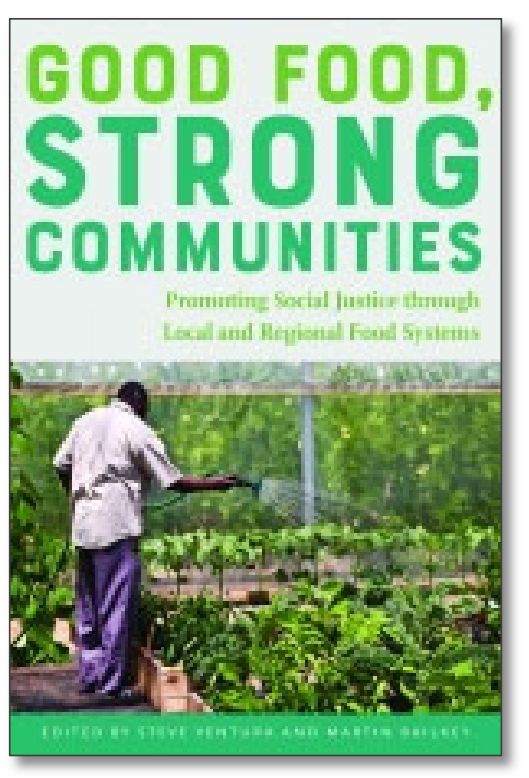

Submitted September 1, 2018 / Revised November 26, 2018 / Published online February 22, 2019

Citation: Crone, A. (2019). Strong book on building community through food [Book review]. Journal of A griculture, F ood Systems, and C ommunity D evelopment, 8(4), 221-222. https:/ / doi.org/ 10.5304/ jafscd.2019.084.014

Copyright ( 2019 by the Author. Published by the Lyson Center for Civic Agriculture and Food Systems. Open access under CC-BY license.

G ood F ood, Strong C ommunities: Promoting Social Justice through L ocal and Regional Food Systems is a book borne out of the Community and Regional Food Systems (CRFS) project, which began in response to a United States D epartment of Agriculture (USD A) request for proposals regarding food insecurity. Guided by Wisconsin-based aca-

\footnotetext{
* Amy Crone is the founder and executive director of the nonprofit Maryland Farmers Market Association (MD FMA). MD FMA implements a statewide farmers market matching program, and provides services including technical assistance, insurance, and educational programs. Crone also works to build innovative technology platforms for farmers and markets to accept electronic payments. She is a nationally recognized expert on federal nutrition assistance programs and local food systems. Crone lives on a small farm just outside of Annapolis, Maryland, and enjoys biking, CrossFit, and spending time with her husband and two children, as well as being outside with their animals. She can be reached at acrone@ marylandfma.org.
}

demic institutions, the CRFS has program participants in seven cities (Madison and Milwaukee, Wisconsin; Boston; Cedar Rapids, Iowa; Chicago; Detroit; and Los Angeles). While the book contains examples from all seven cities, it is primarily focused on efforts in the Midwest. I have participated in a number of such regional efforts, including food policy councils, and have both responded to and reviewed USD A proposals focused on food insecurity. My focus is on the Mid-Atlantic region, but I have traveled across the country working on farmers market and food system efforts that are coupled with social justice. This book was of interest as I hoped to find inspiration for our work in Maryland and the region.

Consistent themes running through and connecting all fourteen chapters are valuable presentations, analyses, and reflections on building equita- 
ble community partnerships. These chapters, each written by different authors, cover the topics of food system change, land tenure for urban agriculture, urban food production, food distribution, food processing, markets, the consumer, soil, food justice, collective impact, education, planning, culture, and innovations. O ne weakness of the book is the lack of inclusion of failed efforts and an analyses thereof; this would be illustrative of how food systems work can evolve over time as conditions change. Furthermore, a few of the examples included have now closed down- most notably Growing Power in Milwaukee.

In each chapter, several perspectives on a given topic are presented, thus allowing the reader to gain sufficiently detailed knowledge to have a fuller sense of the challenges and opportunities on such intransigent food systems issues such as food security, affordable land, food access, regional distribution, healthy food supply and demand, collective impact, policy, and change. A plethora of examples help illustrate how some groups have succeeded in improving their community food systems, while others are still working toward dismantling historical inequities and finding the right framework for change. Monica Theis's chapter on "The Consumer" provides an insightful dissection of the oversimplification of food activists' and writers' messages on what constitutes healthy eating and why it is not enough. Theis then continues to elaborate on the complexities of "the farm-totable continuum" (p. 126) for distinct consumers, and adeptly defines food literacy in the context of improving healthy eating. The chapter concludes with the successful work of the food pantry at Middleton O utreach Ministry in western Wisconsin. This pantry has accomplished what most do not: providing fresh food and community education while simultaneously moving food quickly to avoid spoilage and work within space limitations.

The chapter on federal policy by Lindsey DayFarnsworth and Margaret Krome is one of the best and concisely articulated summaries of the creation of federal food policy I have read in recent years.
Including the role of administrative implementation as well as defining the relative authority of federal, state, and local governments leads into an illustrative example. The authors demonstrate how policy interventions in each phase of the food system can affect economic development incentives, licensing and regulations, and programs and services. This chapter should be required reading for anyone working in the pursuit of food systems and policy change.

The book provides a wide variety of perspectives, and readers may find the specific interventions to be most informative. These include but are not limited to the chronicling of the D etroit People's Food Cooperative, NeighborSpace in Chicago, the Los Angeles Food Policy Council, Community $\mathrm{G}$ roundWorks O rchard Project, DudleyG rows in Massachusetts, and others. $\mathrm{G}$ ood Food, Strong C ommunities is a good reference to have on hand as a tool to understand what efforts have been put forth toward community-based food security, even though some of the entities described in the book are no longer in operation.

This book is an excellent primer on the various complexities of food systems work, and how there are many links in the food chain that can be improved to sustain a more robust local food economy. The editors have done an outstanding job of providing subject matter experts to cover each topic. The chapter authors do not gloss over the challenges of such work, but rather present them as opportunities for improvement. The only weakness of the book may be that it paints too rosy a picture of social justice through regional food systems; there is little mention of the struggles and failed efforts that have occurred in the area covered. G ood Food, Strong $C$ ommunities is an excellent entry point into the complex work of food systems change. It is a worthwhile read for both newcomers to the field and seasoned experts. All readers will benefit from the topical organization of the book, as well as the focus on social values and the conversational tone that is sometimes absent from academic writing. 